\title{
Technology upgrading through co-creation of value in developing societies: Analysis of the mobile telephone industry in Bangladesh
}

\begin{abstract}
The use of various forms of ICTs (information communication technology) such as mobile telephones can foster the socio-economic progression of developing countries. Contextually appropriate design and use are needed for ICTs to deliver value to various parties within the socio-economic spheres of developing countries who have different needs and wants compared to those of the developed world. There is however scant empirical evidence of how various stakeholders symbiotically interact and create value in developing countries where large multinationals have limited access and engagement. Drawing on the theoretical lens of co-creation of value our paper examines how technology upgrading is achieved in the context of the Bangladeshi mobile telephone industry. In doing so this paper suggests technology upgrading can be achieved even without some of the key prerequisites such as financial, institutional, infrastructural facilities cited in existing literature. The findings offer useful theoretical and policy implications by providing deeper understanding of the interactions and inter-relationships of those who have involvement in the value creation for mobile telephony and contribute to the development of effective business models and technological innovations for these marketplaces.
\end{abstract}

\section{Introduction}

The adoption and use of Information and Communication Technologies (ICT) can enable developing countries to leapfrog stages of development by improving the quality of their citizens' lives and facilitating and fostering their overall socio-economic progress (Kapoor et al, 2015; Pick et al., 2014; Walsham, 2010; Heeks and Jagun, 2007; Bayes, 2001). Technological innovations and applications such as the Internet and mobile telephony, for instance, have the potential to contribute to human development and increase market efficiency (Thapa and Sæbø, 2014; Donner a Escobari, 2010; Rashid and Elder, 2009; Marsical, 2005; Fors and Moreno, 2002). The influence of global consumer culture and the subsequent embodiment of a smartphone-enabled and induced lifestyle have had significant influence on the population of emerging and developing countries, indicating the need for further research to assess and analyse the design and upgrading of mobile telephones (including smartphones) and their applications in developing societies. Such studies will 
benefit policy formulation for sustained and optimum growth engendered by technology upgrading and offer useful insights to technology developers and marketers.

Technology upgrading, also known as industrial upgrading, involves specialisation of a country's knowledge base, which increases its capacity for value generation (Ernst, 1998). It is a multidimensional and multi-level process that goes beyond $R \& D$ and relates to interaction with the global economy (Radosevic and Yoruk, 2016). In other words, upgrading refers to a gradual shift in the development and the use of technology toward a more sophisticated level. Existing literature suggests that technology and industrial upgrading require coordinated strategies and structural changes, leading to systematic development of technology at firm and industrial level (Ernst, 2008; Yoruk, 2013; Ernst, 2014; Radoseic and Yoruk, 2014). While this remains the case in more creative economies, which normally have more structured and organised government strategies along with significant contributions from small and large firms, lower income countries such as Bangladesh may not have similar scenario due to a lack of firm-level initiatives and co-ordinated national policies (Mostafa and Klepper, 2017; Razzaque, 1997).

Bangladesh, being a lower income country despite its potential in a number of sectors, has not quite achieved maturity in industrialisation. With its growing middle class consumer segment, Bangladesh has experienced a surge in consumer culture and increasing demand for electronic goods. At the end of June 2017, the numbers of mobile telephone and internet subscribers in Bangladesh were 135.982 million and 73.347 million respectively ${ }^{1}$. Despite this growth in demand, there is little evidence of direct engagement with the market from multinational ICT companies such as Apple, IBM or Google. As a result, this huge market is left with an extended part of the global value chain of these large multinationals, such as mobile phone network providers, distributors and smaller support service providers, who may or may not have direct authorisation from and engagement with the likes of Apple, IBM, HTC or Google. Further research on the market dynamics in this industry would offer useful understanding of how various actors in the harness the market potential and co-create the value through mutual and reciprocal cooperation and fulfilment of needs.

By interviewing industry experts, multinational company employees, small traders and entrepreneurs, this paper looks into the co-creation of technology upgrading and how it relates to various stakeholders and their interrelationships. In so doing, the paper analyses

\footnotetext{
${ }^{1}$ http://www.btrc.gov.bd
} 
how less developed countries can experience technology upgrading at the retail-consumption level with or without large multinational companies' strategies and governmental policies.

\section{Literature review}

This study aspires to advance our understanding of how the technology upgrading in mobile telephone industry of a developing country can be achieved through generating value for various parties and contribute to the socio-economic wellbeing. As such the research is distinctive by virtue of its utilisation of three major streams of scholarship: (a) ICT for development and (b) technology upgrading and global value chain, (c) co-creation of value. Accordingly, the review of the literature takes cognisance of the aforementioned canons.

\section{ICT and development}

ICT can play important roles both as an industry sector to drive economic growth and as an enabler to help achieve other goals in areas such as education, health and governance (Donner, 2006; Foster and Heeks, 2013; Grenshaw and Robinson, 2006; Willis and Tranter, 2006)). Hence, economic development can be achieved through either or both ways: the commercial proliferation of ICTs and their use in development activities.

Scholars (Dey et al., 2016; Kapoor et al., 2015; Prahalad, 2012) point to the success of ICT as a whole and the mobile phone industry in particular as proof that market opportunities exist in developing countries and their citizens are both willing and able to adopt new technologies. Furthermore, the mobile phone has opened up new opportunities for supporting businesses and created space for the development of new business models as well as innovations in areas such as mobile banking (Rahman et al., 2017). Village Phone in Bangladesh (Rashid and Rahman, 2009) and Vodacom Community Services in South Africa (Mutula and Mostert, 2010) represented a rather different approach. This involved mobile phone companies and either government or NGOs supporting local entrepreneurs to set up phone shops which sold mobile access to rural or disadvantaged communities (Aminuzzaman et al., 2003; Reck and Wood, 2003). These efforts provided affordable access to improved communications, better access to information and reduced the need for travel.

While the increasing penetration of mobile phones can be regarded as prima facie evidence that access to mobile telephony at current prices is improving people's lives, it is important to understand how the sustainable and continuous improvement of the technology in developing societies can be ensured and achieved. 
As such, a shift of emphasis is suggested to focus on the development and use of technology at the market level in relation to the wider mass in developing countries, which can not only expand the market potential of large multinationals, but also contribute to the capacitybuilding and wellbeing of people belonging to various strata of the economic pyramid (Viswanathan and Sridharan, 2012; Donner, 2008; Aker and Mbiti, 2010).

\section{Technology upgrading and global value chain}

The previous section discusses the scholarship of ICT for development and the narrative surrounding ICT's contribution to the development of human capital and capabilities that have pervasive impact on developing nations. Furthermore, scholars also suggest appropriate and bottom up approach to designing ICTs (Alalwan et al., 2015; Dwivedi et al., 2007; Jackson et al., 2005) which would not only lead new innovation, but also ensure better use and impact. This is where ICT for development can be linked with technology upgrading.

The concept of technology upgrading and its implications on society, economy and on business in specific has been well-established in the literature (Rostow, 1960; Chenery and Syrquin, 1975; Von Tunzelmann, 1995). As discussed earlier technology upgrading refers to a shift to improved design and use of technology within a certain industry. Technology upgrading requires a broader understanding of innovation which goes beyond R\&D (Lee, 2013), as it may involve contributions of various entities within the global value chain and local organisations and government (Ernst, 2008) and changes in various dimensions such as technological, industrial, organisational (Jindra et al., 2015). As such, technology upgrading is influenced by factors that can transcend national borders as it embodies international trade and investment flows (Ernst, 2008; Fu et al. 2011, Lall, 1992; Radosevic and Yoruk, 2014).

Nevertheless, technology upgrading is an outcome of the change in design, development and use of technologies within firms, across industries and national boundaries. The change can be of different types depending upon the nature of innovation such as incremental and application and diffusion of innovation such as leapfrogging (Kim, 1997; Hobday, 1995). The incremental change of technology can be achieved through different ways such as importing of technology and the creation of original R\&D. However, converting $R \& D$, innovation and production capabilities to the appropriate level of productivity can still remain a major challenge for some countries (Kravtsova and Radosevic, 2012). Modular, architectural and radical changes are the other types of innovation that range from modular modification to the 
changes in both technology components and architectural design. Leapfrogging method on the other hand can be cited as an alternative, as developing countries can skip stages of technology development and stimulate their socio economic progress(e.g. Perez and Soete, 1988; Lee and Lim, 2001). It is often suggested that the use of ICT can enable developing countries to leapfrog the stages of industrial development (Hobday, 1994). Nevertheless, if technology upgrading is to make a long term sustainable impact on a countries' productivity, it needs to be compatible to and integrated with the resources, know-how, capabilities and industrial processes of that country as suggested in extant literature (Qiu et al. 2013; Fu and Gong, 2011). The models for technology upgrading and resulting economic development can be discussed in this regard.

The flying geese model is widely cited for explaining and analysing the technological and economic development in the Far East. However, the model does not fully work out as countries such as South Korea and ASEAN (Association of South East Asian Nations) nations that departed from the Japanese model of protecting infant industry as they became increasingly open to inward FDI (Ozawa, 2003). India, one of the other Asian emerging countries adopted trade and industrial liberalisation by allowing foreign direct investment, improving market efficiency and identifying and creating sectoral developments (Ernst, 2008).

Although foreign technology transfer may be beneficial for technology upgrading in the initial stage, collective indigenous accumulation can be crucial for developing countries ( $\mathrm{Fu}$ and Gong, 2011). Furthermore, import substitution and development of production capability and new forms of software support have been cited as significant milestones in emerging economies' journey to achieving technology upgrading (Franco et al. 2011; Fu et al. 2011). However, the changing nature of new technologies coupled with the proliferation of global value chains leads to new patterns of technology upgrading (or lack of it) about which we have limited in-depth knowledge

With globalisation and advancement of information technology, among others, competition in the global markets has increased. By implying global value chain strategy, a business firm can effectively manage their production strategies and can manufacture high value products at minimum cost. With effective integration of local sources of competitiveness (PerezAleman, 2011; Ritchie, 2010; Del and Rungi, 2015), technological adaptations (Barringer, 2000), national innovation capability (Lundvall, 2010) and skill development (Pavlinek and 
Zenka, 2011; Kaplinksy, 2004; Humphrey and Schmitz, 2001; Porter, 2000) Literature has identified products and process or functional (Pavlinek and Zenka, 2011; Gereffi, 2004), inter-sectoral relationship (Gereffi, 2004) and its effect on government policies (Schmitz, 2004, Humphrey and Schmitz, 2006) as an important component of global value chain.

However, we argue that the concept of value used in the mainstream operations management research does not fully capture the customers' perspectives as more and more industries are increasingly emphasising on value generation through effective and efficient business-tocustomer and customer-to-customer interactions. As such we look at the co-creation of value that has gained currency in recent management and marketing scholarship.

\section{Co-creation of value:}

Prahalad and Ramaswamy (2004) challenge Porter's (1985) traditional value chain concept, as it does not explicitly consider customers' role in the value creation process. The complex nature of industrial development and market dynamics constituted by informal players in developing societies (Dey et al., 2016; Rashid and Rahman, 2009) are also not considered in the traditional value chain concept. Essentially, all parties involved in the production and consumption processes exchange resources and ideas to create value, and hence value creation is not the result of producers' endeavour alone (Vargo and Lusch, 2008). Saarijarvi et al. (2013) suggest that customers should not be viewed as passive targets of marketing activities, but as active operant resources that can create value. It is argued that by involving customers in the product development and innovation processes, marketers can enhance their product value. The question is - who then co-creates value? Co-creation occurs when two or more groups influence or interact with each other (i.e. customers and the organization) (Grönroos and Voima, 2013).

Value co-creation should be characterized through the roles of the customer and the firm and the recognition of the value spheres that include the firm and the customer (Grönroos and Voima, 2013). As such, the customer-firm dyadic interrelationship may not be sufficient, especially in developing societies where customers often do not have close interactions with large firms, dealing instead with their fellow community members and small and local businesses, which emerge as the de facto service providers. For instance, local tea-shops in rural Bangladesh offer top-up services for mobile telephones (Dey et al., 2013). Thus, the process of this collaboration between marketers, customers and other relevant businesses for 
improved innovation, design and development of products has defined the co-creation of value, as suggested in contemporary scholarly works (Ravald and Grönroos, 1996; Prahalad and Ramaswamy, 2004; Grönroos and Voima, 2013).

Nevertheless, value co-creation still remains an elusive concept. While scholars in this field hold different opinions regarding the nature and modality of value co-creation, existing models (e.g. Prahalad and Ramaswamy, 2004; Chen and Nath, 2004; Anderson and Rosenqvist, 2007) offer a wide range of perspectives on this process. The DART model suggested by Prahalad and Ramaswamy (2004) provides the basic foundation in this regard and suggests dialogue, access, risk reduction and transparency as the four necessary conditions for value co-creation. Payne et al., (2008) suggest a process-based framework by identifying the three major processes in value co-creation: the customer value-creating process, the supplier value-creating process and the encounter process. Hence, value can be created at the customer end, at the supplier end and/or during the encounter between the two. Most of the academic literature focuses primarily on value creation induced by suppliers and/or conducted at the encounter stage. There is only partial understanding of community engagement (Hollebeek and Brodie, 2009; Pongsakornrungsilp and Schroeder, 2011) and individual and situational factors (Takenaka and Ueda, 2008; Sandström et al., 2008) which influence the creation of value in remote situations (that do not involve direct personal interaction between marketers and customers).

\section{Synthesising ICT for development, technology upgrading, global value chain and co- creation}

Current literature on technology upgrading indicates to the potential of ICT in enabling and fostering economic development in the context of emerging countries (Hobday, 1995; Ernst, 1998). However, ICT for Development literature has not fully utilised technology upgrading theories leaving scopes for further empirical research and conceptual nourishment that can benefit both ICT for development and technology upgrading scholarships.

Recently, the understanding of technology upgrading has been explored in the frame of global value chain (Radosevic \& Yoruk, 2016) as scholars seek to conceptualise technology upgrading as a three-dimensional process: 1. intensity of technology upgrading i.e., different types of innovation activities, 2. spread or breadth of the technology such as the diversity of 
technological knowledge, types of supporting infrastructure and, 3. knowledge inflows into the economy via a variety of channels such as trade, foreign direct investment and global value chain. Previous literature (Bruno and Campos, 2013) emphasises on the link between FDI and technology upgrading. Others such as Yoruk (2013) attributes learning through value chains related to process, product, and functional upgrading as an important contributor to technology upgrading. In addition, she highlights the importance of organisational capabilities and firm's structure as a significant dimension of technology upgrading. Technology upgrading can also happen in the industry level through symbiotic interrelationships between various firms. However further research is needed on how value is created through technology upgrading as a function of inter-relationships and interactions amongst various parties involved in an industry particularly in the context of smaller nations that have limited infrastructural, financial and institutional support.

For instance, Vargo, et.al, (2008) argued that value is derived through the integration and application of resources (information technology) in a specific context such as improving the adaptability of systems by allowing integration of resources that are mutually beneficial. In an insightful case study with IBM, Spohrer and Maglio (2008) demonstrated that technology upgrading should be combined with business, social, and client (demand) innovations necessary for co-creation of value. Similarly, Prahalad and Ramaswamy (2004) argued that transparency and access are vital for value co-creation which needs investment in technology upgrading as well as investments in socializing managers and changing managerial practices. Furthermore this value being the outcome of the process feeds back to the industry and users. ICT for Development literature can also take this perspective to assess the outcome of technology development, diffusion and use.

The actors involved in technology upgrading and value co-creation also need to be reassessed. The roles of government and profit seeking enterprises have been highlighted in existing literature. However, there may well be scopes for spanning the horizon. For instance, the role of NGOs appears to be crucial in implementing ICT enabled projects in emerging countries. Prahalad and Hart (2002) and recently London (2016) describe the business models of companies that succeed in the low end of the market. At this low end, profits are not made through the traditional pursuit of high margins but are driven by volume and capital efficiency. Collaboration with NGOs plays a part in this. Interestingly, Karnani (2012) argues that even if there is an opportunity in selling to the poor, the best suited companies to make the most of these opportunities are usually small or medium sized local ones and not MNCs. 
Again, scale of NGOs is an implicit assumption in terms of suitability of collaboration following on from Karnani’s argumentation.

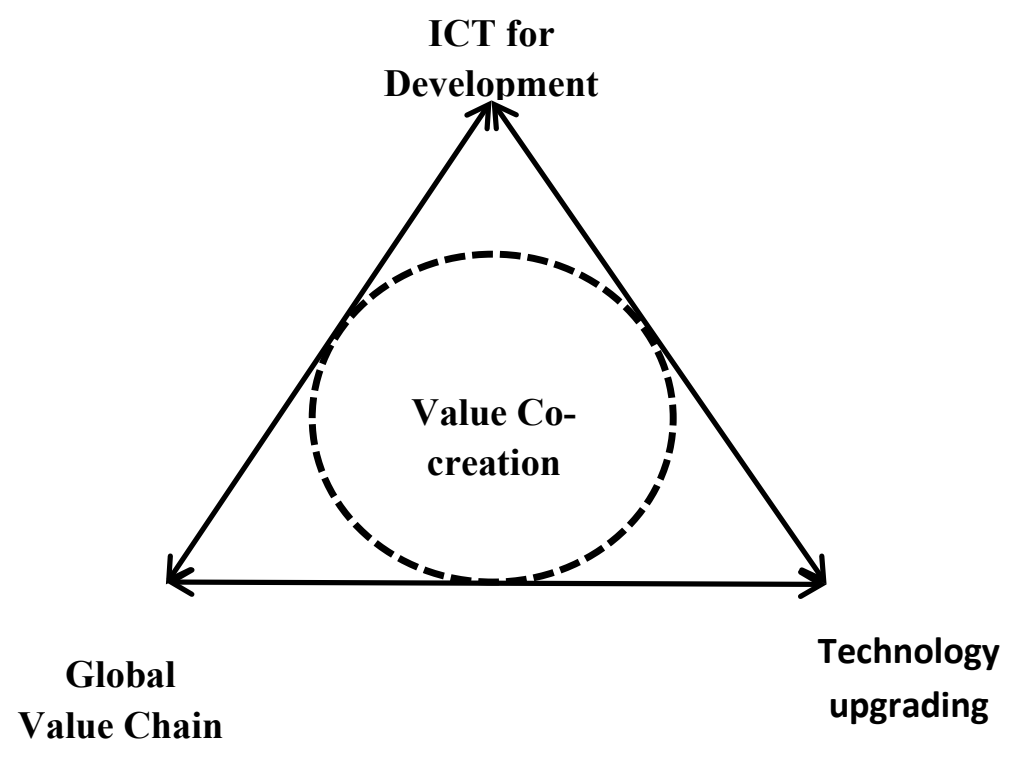

Figure 1: Conceptual framework for technology upgrading contributing to value co-creation in ICT sectors in emerging countries

Figure -1 summarises the conceptual framework by linking technology upgrading, global value chain and ICT for Development. ICT for Development, technology upgrading and global value chain conceptually complement each other. The co-creation of value is to remain at the centre of this interaction in order for these components to achieve optimum outcome in an emerging nation. Hence, the current literature on technology upgrading with regard to the global value chain can be advanced and enriched with the inclusion of co-creation emanating through symbiotic interrelationships of various parties and systems in emerging and developing societies.

As such this paper aims to enquire how technology upgrading through co-creation of value is achieved in the context of mobile telephone industry in Bangladesh. In more specific terms this paper seeks to identify and analyse the actors and their interrelationships that shape the processes and outcomes of value co-creation in the design, development and use of mobile 
telephone services in Bangladesh. This research embraces interpretivist philosophy (as discussed in the following section) with an open mind to probable outcomes. As such, the paper does not hold any specific hypotheses. Nevertheless, from the review of literature we have been led to assume that government policies, SMEs and NGOs in addition to large multinationals are likely to be involved in the co-creation process.

\section{Methodology}

The research strategy was designed to obtain a deeper understanding of the policies and processes leading to the development, advancement, diffusion and use of mobile devices and applications in Bangladesh. An interpretivist approach is deemed appropriate in this regard, as it offers the opportunity to identify and analyse the processes, challenges, outcomes and iterations that constitute the dynamics and kinetics of technology upgrading. As such, indepth interviews with policy makers, industry experts, and employees from commercial and not-for-profit organisations were conducted to gather a more holistic understanding.

Secondary research on relevant scholarly works, government policy documents and consultancy reports, as discussed earlier in this paper, indicated the roles of key organisations that have bearing on technology upgrading. In total, twenty seven (27) in-depth interviews were conducted (please see Appendix 1 for detailed respondent profiles). The criteria for selection were guided by maximum variation purposive sampling to cover the relevant expertise and experiences of different groups and individuals. Two main cities - Dhaka and Chittagong - were selected for the interviews based on the convenience of the respondents. A combination of face-to-face, telephone and Skype-mediated interviews were conducted to ensure convenience and optimise response rates. On average, each interview took between forty-five (45) minutes and an hour.

Different interview protocols were used for different types of respondent. However, certain issues, such as their opinions regarding government policies, historical development of the industry, current and future challenges and ways to address them, were central to all the interviews. Appendix-2 summarises the interview protocol.

Five (5) of the respondents, all of whom were employees from multinational companies, did not provide consent to record their responses. Otherwise, the interviews were recorded. Eleven (11) interviews were conducted in Bengali and the rest in English, although 
respondents all are Bangladeshi. Interviews were transcribed and when necessary translated to English before being recorded in NVivo

Template analysis was applied for data management. The transcripts were coded using the NVivo software package. Analysis of data started with the development of a coding template and identification and classification of themes and constituting codes. In this research, four broad themes were applied: technology innovation, technology advancement, challenges in technology development and the inter-relationship between various actors and institutions. Against each theme there were two sets of codes. While some of the codes were theory driven, others were data driven, as suggested and practiced in previous scholarly works (Chen et al., 2011; Fereday and Muir-Cochrane, 2006). Once the information related to the research objectives had been identified, data were analysed using a constant comparative method. The emergent themes were then compared with the extant literature.

\section{Findings:}

As discussed in the methodology, our initial interviews with industry experts and concurrent secondary research defined the boundary and key components of this research, which also lent itself to the formulation of the structure of the findings section. As such, this section revolves around a number of actors and their inter-relationships. We have analysed both macro- and micro-level issues and actors that shape the industry.

\section{Mobile telephone industry in Bangladesh - the roles of large local and multinational companies}

The smartphone market of Bangladesh is dominated by local brands, which cumulatively hold more than $60 \%$ of the market share, as of the end of the second quarter of $2017^{2}$. In 2017, Symphony, which is leading the market with more than $40 \%$ market share, imported a staggering 11.60 million handsets (of which 3.4 million were smart phones), thus securing the first spot in total handset sales in terms of number. Samsung stood second, importing 1.5 million handsets. In terms of revenue from total handset sales, Symphony was also the market leader, followed by Samsung ${ }^{3}$. Though Symphony imported more smartphones, Samsung got the upper hand in total revenue from smartphone sales. Essentially, this was due to the price

\footnotetext{
${ }^{2}$ www.dhakatribune.com

${ }^{3}$ www.thedailystar.net
} 
tags of smartphones bought by these two different brands. While Samsung and Symphony are in head-to-head competition, Huawei is steadily marching to the third spot.

Large local companies have established their brand names to the bottom of the pyramid and mid-segment markets. Additionally, to ensure seamless supply of the products to the Bangladesh market, local companies have established facilities to assemble handsets and their parts. As such, the large MNCs operating in this industry have gradually lost market share. The local companies have improved their market positioning by expanding the market both geographically and demographically. The complex development and dynamics of the market could be evident through the comments of various participants:

Participant no. 12: "Samsung and Apple hold strong brand awareness among the potential smartphone customers particularly with most of the urban customers. However, despite such strong top of the mind share of these international brands, local brands have cut through offering product with "me-too" features in a significantly affordable price compared to those large brands. This is putting the brand loyal customers in a very challenging situation and eventually many customers have opted for the cheaper local brands."

Local brands like Symphony and Walton also have strong customer service networks through which they offer after-sales services. Brands like Samsung and Huawei have also established customer service centres; however, their capacity is very limited considering the number of handsets in the market. Moreover, the nature of aftersales service contracts and expenses has encouraged many customers to opt for alternative service centres, which are established and run by SMEs in certain prominent locations. Nevertheless, the market is still growing and holds strong promise for future. The gross domestic product of the country had increased by $7.2 \%$ in $2017^{4}$ indicating the current and future potential of the market. In the changing global competitive environments multination companies need to have further engagement with the emerging markets. With the Chinese market having slower growth Apple appears to have intensified their interest in Indian market. After the recent economic and tax reform in India, Apple has reduced the prices of all of their iPhone products in India and have received positive market response ${ }^{5}$.

\footnotetext{
${ }^{4}$ https://www.adb.org/countries/bangladesh/economy

${ }^{5} \mathrm{https}$ ://economictimes.indiatimes.com/tech/hardware/gst-impact-apple-cuts-prices-of-all-iphone-models-inindia-by-up-to-7-5-per-cent/articleshow/59400840.cms
} 
From the above discussion it appears that multinational enterprises maintain their presence in Bangladeshi market. However, they are not fully active in terms of engaging the market and exploring its potential.

\section{Small and medium enterprises - key contributors to value and innovation in the mobile telephone industry}

These SMEs offer a variety of mobile phone services, including repairing hardware, providing spare parts, troubleshooting software and unlocking handsets. Bangladesh does not have adequate formal vocational institutes/programmes for aspiring engineers/technicians ${ }^{6}$. The development of skills and dissemination of knowledge in the smartphone repair and troubleshooting sector take place through informal apprenticeships and peer to peer support. Currently no Bangladeshi further/higher education institute offers training on smartphone troubleshooting. As two participants commented:

Participant no. 6. "The mobile phone industry is badly in need of a skilled labour force, not only to set up domestic production units but also to offer efficient after-sales services. Presently the mobile repairing industry is run by SMEs who employ or develop partnerships with semi-skilled but experienced engineers who have hardly any formal training”.

Participant no. 11. "Regarding the repair of mobile handsets, there remains a classic example of intra-industry knowledge transfer, as most of the service engineers have acquired the skill through apprenticeship, observation and experience. The so-called senior engineers get their skills through their work experience with international mobile brands, and later impart them to their apprentices. After this 'training', these apprentices start their own service centres (which are SMEs) or work with other SMEs. Over time, the apprentices become experienced engineers and pass on the skill to newbies."

In addition, it has been noted that a large volume of smartphones are brought to Bangladesh through informal means, as non-resident Bangladeshis send their relatives second-hand/new handsets. These informally sold sets open up business opportunities for smaller traders who jailbreak the smartphone operating systems to break the country codes. Owners of secondhand devices also need to visit these small traders for troubleshooting services such as

\footnotetext{
${ }^{6}$ http://www.dhakatribune.com/opinion/op-ed/2016/09/09/skills-for-life/
} 
resetting their iTunes/iCloud passwords, which are usually unfamiliar to less tech-savvy customers. This lack of technical expertise of the users and the market dynamics are addressed by smaller entrepreneurs, as Participant 17 mentions:

Participant 17: "I started my business as a fax/phone service provider in the late 1990s. In those days there were no mobile telephones, and not many people had landline telephones either. When mobile telephones first came, I started to do flexiload (an electronic top-up service). It turned out to be a good business. I still do that, but additionally I offer support for smartphone devices. ... People bring their phones sent by relatives abroad, as they do not know how to update software."

Hence, the smaller entrepreneurs respond to the dynamic nature of the industry and make significant contribution to the expansion of the market and the diffusion and effective use of the technology.

The success of the value-added service (VAS) in the mobile telephone industry further highlights the importance of SMEs. The VAS market was worth ten million USD in $2012^{7}$. Value-added services involved mobile telephone based voice and data services that disseminate useful information to customers. For instance, by dialling 789, customers could access a 24/7 medical helpline. Cell bazaar was a popular VAS that enabled customers to trade their goods. It was a customer-to-customer mobile business similar to a mobile version of eBay. Participant 4, a senior manager of a telecom company, highlights the impact that VAS brought to the lifestyle of the general populace:

Participant no. 4: "The technological boom of the VAS market has improved people's lives by offering various services, which range from contents and information about lifestyle and entertainment to access to various life-easing services such as health-care and financial services."

VAS was also a significant development as far as the use of technology was concerned. Consumers found new opportunities to explore the use of mobile telephones that transcend the boundary of hardware devices and started to believe that mobile telephones offer lot more than voice calls. It also had important implications for small and medium enterprises and software developers, who began to make their way in the mobile telephone industry. As participant 19 (an SME owner) explains:

\footnotetext{
${ }^{7} \mathrm{http}: / /$ www.thedailystar.net/news-detail-229785
} 
Participant no. 19: "The mobile telecom service has not only brought in new technology in this sector but has also contributed to the economy of the country through the establishment of SMEs. These enterprises facilitate the expansion of the industry by selling accessories related to the handheld devices and loading talk-times/credit to ensure seamless connectivity."

Over this period, the VAS market has been replaced by the apps market because of the availability and monumental growth of smart mobile devices. The evolution of the VAS and apps markets certifies a shift of power as a result of technology adoption. Earlier, the industry developed and flourished around hardware, including the infrastructure and handheld devices. The advent of VAS and the apps market has gradually shifted the paradigm from a hardwarebased, capital intensive system to a service-oriented system, which is certainly conducive for the economic development of a country like Bangladesh. Participant 3, a mid-level manager of a telecom industry, emphasises the importance of the VAS in the Bangladeshi mobile telephone industry:

Participant no. 3: "Earlier, the mobile telecom sector was mostly dominated by hardware, such as the excellence in the infrastructure (network strength) and sophistication in handheld devices. However, the arrival and rise of soft technologies in the form of the VAS and apps industries have revolutionised the industry."

The smartphone market has created opportunities for localised apps in Bangladesh market. Inventive and contextually appropriate apps such as ride hailing (Pathao, Amar bike, Ezzyr), food delivery (Hungry Naki, Food Panda), balance recharging (Udoy, Easy.com.bd), financial services (banking apps), medical (CriticaLink; Tonic, Doctorola, Rx71), language (Lipikaar, Avro) and shopping (bikroy) offer value to customers and relevant businesses. Of all these apps, Pathao could be regarded as the local version of Uber; however, unlike Uber, Pathao uses motorbikes for ride sharing and delivery, as motorbikes can move faster through busy traffic. This is particularly helpful for young office goers to avoid the horrendous traffic jam in the streets of the capital city Dhaka. Pathao, one of the most successful start-ups in recent years, started initially as a web-based application but experienced success with its mobile phone based apps. ${ }^{8}$

\footnotetext{
${ }^{8}$ http://www.thedailystar.net/bytes/top-5-uber-alternatives-bangladesh-1321312
} 
In summary, SMEs play a crucial role in technology upgrading by working as a bricolage in the industry. They fill the vacuum left by large multinationals and contribute to technology upgrading by offering contextually appropriate services and educating people. In other words, they help to create, support and sustain the platform for the design, development and use of technology.

NGOs and not for profit organisations - key stakeholders for ICT for Development and social innovation through mobile telephony

In the mobile telecom sector of Bangladesh, which is dominated by MNCs, the local government organizations, NGOs and international donor agencies work in a very integrated way. The mobile telecom sector is the main backbone of communication for people from all walks of life, irrespective of their organizational orientation. The pervasive diffusion of the technology and its subsequent impacts on the community have increased its stakeholders and expanded the periphery of the industry over the years.

Participant no. 9: "The multinational companies that provide mainly network services have close professional ties with government and other NGOs through both formal and informal chains. However, the MNCs that deal with smart devices have hardly any formal links with the NGOs."

There has also been larger cooperation between commercial and not-for-profit organisations. Government's participation through public-private joint projects has also increased.

Participant no. 10: "The Government has signed several memoranda of understanding with various multinational companies, universities and local and international NGOs for the purpose of creating and delivering services to the public. The creation of eservice delivery is one of those outputs, which was generated through a tripartite initiative between Government, the telecom industry and local NGOs."

A number of globally renowned NGOs, such as BRAC (www.brac.net), Grameen Bank (grameen.com) and Asa (asa.org.bd) originate from Bangladesh, which is proud to have been associated with NGO-led social reform programmes and social innovation for decades. One of the most successful social innovations led by joint commercial and not-for-profit organisations in Bangladesh is bKash, which is a mobile platform based financial service (MFS). 
The development of bKash has followed a multi-stakeholder approach to operating social innovation ventures, which yielded success in the past. Its management team includes an independent private researcher agency, NGOs, mobile technology providers, and government. Unlike many other MFS worldwide (such as Easypaisa in Pakistan by Telenor, Airtel's mobile money in India and Sub-Saharan Africa, Dialogue in Sri Lanka), bKash is not tied up with any mobile network operator. bKash acquired its market by dint of being a specialized organisation built to deliver mobile financial services, with a shared vision and an enabling and flexible regulatory environment ${ }^{9}$. Established in 2011, bKash rose to popularity and earned customers' trust very quickly due to its mobile platform, ease of use, broad acceptance, vast availability, diverse group of investors, supportive regulatory environment, and strong brand presence (Davidson, 2015). Presently, in the mobile financial services market of Bangladesh, 20 organisations have received license to operate and 19 of them are running their operations; however, bKash and Rocket (another mobile financial services brand initiated by a commercial bank) hold $85 \%$ and $10 \%$ of the market share respectively ${ }^{10}$. bKash has more than 24 million registered customers. In June 2016, the total number of organisations that used mobile money exceeded 700 and the number of merchants accepting bKash payments now exceeded 30000. The total transaction volume in June itself exceeded USD 7.5 million $^{11}$.

Bangladesh has experienced one of fastest growing mobile money services thanks to bKash as it has become the second largest mobile money provider in the world after Kenya's mPesa $^{12}$. Although bKash has been criticised for causing market disruptions and being a disruptive social innovation in the financial services sector, it is commended as a contextually appropriate social innovation, as it aims to achieve technology mediated financial inclusion.

Participant no. 10 "The MFS market in Bangladesh is growing at an exponential rate thanks to the government's favourable policy, available technology in the form of ICT and mobile networks and logistics. However, it is a matter of great concern that the level of competition in the MFS market is not fair: this should be overlooked for the greater benefit of the relevant stakeholders".

\footnotetext{
${ }^{9}$ https:/www.gsma.com/mobilefordevelopment/wp-content/uploads/2017/03/GSMA_State-of-the-IndustryReport-on-Mobile-Money 2016.pdf

${ }^{10}$ www.newagebd.net; www.bb.org.bd http://www.thedailystar.net/business/mobile-money-monopolisticmarket-official-1358230

${ }^{11} \mathrm{https}$ //globalpaymentsummit.com/bkash-bangladesh-24-million-customers-using-mobile-money/

$12 \mathrm{http}: / /$ www.dhakatribune.com/feature/2016/02/14/mobile-money-in-bangladesh/
} 
Despite its widespread acceptability, bKash has been in the news for some negative issues, including fraudulence, money laundering, untraceable payments, and use for anti-social and anti-state activities ${ }^{13}$. Recently Bangladesh Bank ordered to close 2,887 centres of bKash over allegations of 'digital hundi' 14

Participant no.16: “...along with the boons of technology there come the banes!! A significant loophole in bKash is that people have used this service for unscrupulous intentions, as after a point, the sender of the funds remains untraceable."

This is a new dimension in the technology upgrading. The role of NGOs has not been highlighted in the existing technology upgrading and co-creation literature. In the context of Bangladesh, it appears that NGOs are closely connected with the development of mobile telephone industry. As such, NGOs can complement the contributions of large multinationals and play a vital role in the innovation and diffusion of technology.

\section{Government policies and regulations}

Since 2009, the slogan 'Digital Bangladesh' has been used as political rhetoric and identified and listed as a means for poverty alleviation. In line with the World Bank's taxonomy of ICT-led development provisions, the Government of Bangladesh (GOB) has also identified and worked on two broader areas: ICT as a sector and ICT as a facilitator for other development imperatives. GOB is committed to applying ICT4D as a means for achieving the Millennium Development Goals (MDG). The first ICT policy of 2002 needed further revision. A lack of coordination and ownership of the projects was cited as the major weakness that inhibited the progression of $80 \%$ of the projects. The revised policy, which is considered to be a pragmatic and visionary initiative, was developed in 2008 . Respondent 27 , who is an industry expert and researcher, says:

Participant 27: "The policy designed in 2008 by Professor Jamilur Reza Chowdhury, an exponent of science and technology research and studies in Bangladesh, was far more pragmatic, visionary and detailed compared to the one we had in 2002. Of course, the first policy had teething problems. The second ICT policy identified the weaknesses within government bureaucracy and recommended more coordination between policies and strategies for implementation."

\footnotetext{
${ }^{13} \mathrm{http}: / /$ www.dhakatribune.com/bangladesh/crime/2017/11/10/safe-biometric-data/

${ }^{14} \mathrm{http}$ //www.dhakatribune.com/bangladesh/corruption/2017/09/15/bb-orders-bkash-close-2887-agent-accountsdigital-hundi/
} 
In 2009 there was a change in the government; the new regime revised the policies, created a dedicated Ministry of ICT and took a range of steps to bring ICT to the core of public and private organisations. These measures coincided with a surge in the adoption of mobile telephony, Bangladesh's connectivity with fibre-optics and the emergence of $3 \mathrm{G}$ Internet coverage.

Participant 9: "The rise of the information superhighway and ease of communication (through mobile phone) throughout the country has encouraged the government to adopt 'digital Bangladesh' and access to information (A2i) policies in association with the MNCs of the telecom sector and local NGOs."

In the last decade, there has been significant development in the digitisation of the government documentation and practices. Participant 10 (an industry expert and government official) reflects on the government's policy on ICT as a sectorial area:

Participant 10: "The Government of Bangladesh puts strong emphasis on technology and innovation; therefore, it considers ICT and its application through smart device apps as a potent tool to deliver government services to people. Considering its importance, government has developed an ICT act and policy: as a result, all the ministries of the government integrate ICT in facilitating their programmes."

ICT has also been identified as a potential sectorial area that can flourish and generate employment and export proceeds. Interview findings and secondary research indicate that ICT as a sector and facilitator complement each other. The success of mobile device led development initiatives has been supported by technological innovation and diffusion. Mobile apps, value added services and Bengali software packages in particular have made notable impacts on enhanced usability and expedited diffusion across the socio-economic strata. Participants 12, a senior academic, considers that the government's ICT initiatives are interwoven with combined and/or concurrent efforts from NGOs and multinational and local corporations that lead to the development of ICT sectors in the form of software development, the establishment of call centres and business processing units, hardware businesses and so forth.

Participant 12: "The Government of Bangladesh, as part of its ICT policy and act, has established innovation cells in every district. Moreover, from its service innovation funds, the government supports various innovative projects from NGOs and other 
organisationswith a view to bring people under the umbrella of technology. ICT-related businesses as a result have mushroomed in recent times. We now have many young entrepreneurs who develop apps for smartphones."

Government's ICT policy considers mobile technology in general and smartphones in particular as central to current and future development. As Participant 9 (an industry expert and government employee) opines:

Participant no. 9: "With a view to bring the services to people, when the government of Bangladesh develops and implements any project, it considers ICT and smart phone apps as an integral part (in many cases, feature phones are also considered). For instance, we can mention the classroom 'management system' app (as part of the A2i project) and the 'Uttoradhikar' app (for the proper distribution of inherited property), which are accessible through webpages and smart devices."

Another significant government policy that has boosted the people's access to the most updated technology is the decision to give licenses for the $3 \mathrm{G}$ and $4 \mathrm{G}$ mobile frequency to mobile network service providers ${ }^{15}$. Initially the state-run mobile network company was given the $3 \mathrm{G}$ license which was later offered to the other private network service providers. The successful adoption of $3 \mathrm{G}$ technology in Bangladesh has encouraged the Government of Bangladesh to introduce $4 \mathrm{G}$ as GOB has approved relevant guidelines with spectrum prices, paving the way for the telecom regulators to stage an open auction in March $2018{ }^{16}$. Availability of such updated technology in a hand-held device has encouraged the increased adoption of smart devices to be used for varied purposes. The $3 \mathrm{G}$ technology has not only increased the speed of wireless data transfer between mobile and fixed ICT devices but has also ensured secured transfer of information. As a result, in addition to the web applications, a myriad of mobile based applications have been in demand which have created opportunities and enhanced people' social and economic well-being. As such, there exists a strong connection between the booming smartphone industry and adoption of $3 \mathrm{G} / 4 \mathrm{G}$ technology.

Hence, the government builds, supports and monitors the ecosystem. The government may not initiate any innovation, but it provides quintessential platform for technology upgrading and development.

\footnotetext{
${ }^{15} \mathrm{http}: / /$ www.btrc.gov.bd/

${ }^{16} \mathrm{http}: / /$ www.xinhuanet.com/english/2017-09/14/c_136609992.htm

http://www.thedailystar.net/business/telecom/4g-internet-service-in-bangladesh-by-march-1519876
} 


\section{Summary findings}

The findings of this research demonstrate that mobile telephony industry in Bangladesh has bespoke contribution to the socio-economic wellbeing of its population. While, entrepreneurial development, banking, health and agriculture have been benefited from the design, development and use of mobile telephony, the contribution of the auxiliary industries has expedited, supported and sustained technology upgrading in this sector. There is an organic and symbiotic ecosystem constituted by the mutual support and cooperation among NGOs, SMEs, large local and multinationals and government institutions. This is what we have described as the co-creation mechanism for technology upgrading. The theoretical implications of these findings discussed in the following section.

\section{Discussion}

Information and communication technologies can be classified as cotechnology that is designed, developed and used through participative contribution and cooperation of various stakeholders such as designers, developers and users (Stevens, 1990). In this paper we analyse the nature and inter-relationships of the actors that constitute the "co-creation of technology upgrading'. Our findings link the design and development of mobile telephony and how it can evolve through the iterative interrelationship between various actors within and across industries. The findings exhibit that small and medium enterprises support and help to sustain the industry and its infrastructure while NGOs assist to develop large scale services that not only help technology diffusion but also widen the scopes for its contribution. Based on these findings, we seek to advance the existing literature on ICT4D (Pick et al., 2014; Foster and Heeks, 2013; Donner and Escoberi, 2010), co-creation (Dey et al., 2016; Prahalad and Ramaswamy, 2004; Payne et al., 2008) and technology upgrading (Ernst, 2008; Yoruk, 2013; Ernst, 2014; Radoseic and Yoruk, 2014) by analysing and weaving the empirical data with multi-disciplinary theoretical concepts.

Accordingly we have developed a model that exhibits the roles and relationships of the various parties involved in the design, development and use of technologies in a developing country. The findings suggest that Schumpeterian R\&D driven industrial development model or the flying geese model of East Asian countries do not fully explain the development of mobile telephone industry and its technological upgrading in Bangladesh. First of all, as it stands despite political rhetoric and government support for ICT enabled projects the SMEs have not received much government support. Most of these firms have very limited R\&D 
investment. Nevertheless, the proliferation of the support industries through innovative software and hardware solutions and contextually appropriate design and development of smartphone apps exhibit that technology upgrading can be achieved by small organisations operating at the end part of the value chain.

As such, smartphone industry and its myriad influences on the socio-economic development are sustained even with limited initiatives from the large multinationals such as Apple and Samsung. Furthermore, we have also critically assessed a popular narrative - that 'information communication technology is a panacea for developing nations'. Although ICT has the strong and clear potential to enable a developing nation to leapfrog the stages of development and achieve greater good for the wider populace across the socio-economic strata, it requires an organic and bottom-up approach to development supported and crafted by appropriate government policies, innovation at the market level, wider industry engagement and contextually appropriated social innovation. The case of bKash further attests that the roles and responsibilities of the large commercial and not-for-profit organisations need to be shaped and determined by effective and appropriate regulatory frameworks that would ensure balanced, ethical and sustainable technology use.

The importance of public-private collaboration has also been highlighted in the cases of East Asian countries (Ozawa, 2009). Nevertheless, the creative means for small traders, entrepreneurs and end users play pivotal roles in both software development and hardware support that meet contextual requirements - this particular case has not been properly discussed and explained in the existing technology upgrading literature. Edison's business acumen and entrepreneurial skills and contribution from various other supporting ventures enabled the development of electricity industry (Millard, 1990; Hughes, 1983). The support from large investors however was the key to the diffusion of innovation in the $19^{\text {th }}$ century USA. In the case of $21^{\text {st }}$ century Bangladesh the entrepreneurial thrust and support of ancillary businesses have equal if not more contribution to the success of diffusion and effective use of mobile telephony. Unlike bigger technologies that have limited contribution from locally developed small and medium enterprises, ICT such as mobile telephony requires symbiotic intra-industry relationships among large and small businesses.

The following components constitute the model and elaborate on the above arguments.

A) Large multinational and local companies and global value chain: As discussed in the findings section, developing countries such as Bangladesh do not often attract large 
multinational companies due to a lack of business and profit potential. Hence, companies such as Apple have limited engagement with the local market. Although the likes of Samsung, LG and Nokia have closer relationships with the market, often their services and outlets are only available in metropolitan cities and urban areas. Large regional (Asian) multinational companies such as Huawei have made good use of the vacuum left by global multinationals. The role of the local distributors is also very important because of the warranty and after-sales support they provide in addition to regular distribution and retail services. The network service providers that are also large multinational enterprises, such as Grameenphone (a subsidiary of Telenor), Robi Telecom (jointly owned by the Axiata group of Malaysia and Bharti Airtel of India), and Banglalink (owned by Telecom Ventures limited of Malta), have direct foreign investment in setting up towers and infrastructures. They also provide high-end smartphones to their top-end customers with after-sales support and other benefits. Hence, the technology upgrading in the large firms is confined mostly to foreign direct investment and operational support.

B) Not-for-profit organisations and social enterprises and social innovation: $\mathrm{Su}$ and Moaniba (2017) suggest fusion of technology originating from different industry can play a vital role in developing designs for outstanding innovation. We argue that the knowledge and expertise within and beyond industrial boundary is also a key factor in this regard. This has been the case in the mobile telephone industry in Bangladesh. Grameenphone, one of the most successful mobile telephone service providers in Bangladesh, emanates from a joint collaboration between commercial and not-for-profit ventures and builds on the worldwide reputation of Grameen Bank. As findings suggest, for the last twenty years Grameenphone and other service providers, along with a number of NGOs, funded by leading global donors, have embarked on myriad social innovations to contribute to the wellbeing of the general populace, which have also received attention from scholars (Rashid and Rahman, 2009; Bayes, 2001). Mobile financial services (bKash), being a topical venture, have also been critically assessed in this paper. While we find the involvement of not-for-profit organisations a useful addition to the industry in terms of channelling attention to public welfare and creating more opportunities for social innovation at various levels of the socio-economic pyramid, the absence of an appropriate regulatory framework impedes the ethical and sustainable success of mobile financial services in Bangladesh. This is where it is important to conceptualise the macro-level inter-relationships between the actors. Technology upgrading can hence be initiated through inter-industry collaboration (between mobile 
telephony and NGO sectors, in this instance); however, it requires an over-arching monitoring and regulating framework that can better be managed at the state/government level. Furthermore, we highlight the importance of a bottom-up approach to technology upgrading where donor agencies and their supporting NGOs' roles in the global value chain need to be incorporated.

C) Small and medium businesses and entrepreneurs: Our findings provide strong evidence to suggest that the global value chain for mobile telephony in a country like Bangladesh is substantially benefited by the formal and informal entrepreneurial initiatives of small and medium businesses. The pervasive use of second-hand smartphone devices gifted by friends and family members of the users living abroad, brought into the country through illegal channels, also opens up the opportunities for a parallel market of support services. These businesses are not a formal part of the industry; however, they make significant contributions to the effective use of its products and also to the expansion of the market. This is where we believe the current understanding of the global value chain and technological upgrading can both be enriched. These small traders also extend the lifecycle of the mobile sets, which otherwise would have been obsolete in the developed world. Our findings have also touched upon issues pertaining to the development of VAS and apps, which, although they are global phenomena, have a special place in the market dynamics of mobile telephony in Bangladesh. Again, these small apps developers for smartphones and the developers of VAS are useful and relevant actors in the market, as they co-create value for the end users and also upgrade the technology by making it more usable and contextually effective. As such, we would argue that the global value chain can contribute to technological upgrading by incorporating these small and medium enterprises, which not only add value to the products and enhance market share for the large multinationals but also advance the technology and ensure its effective use and appropriation. It is important to highlight the dynamic nature of these ventures, driven by inventive and creative visions and changing market needs. Echoing our previous point about a bottom-up approach to technology upgrading and its co-creation, we further argue that in developing societies, these traders remain close to the user community; they have their fingers on the pulse of the users. They provide a bridge between the users and the technology designers, with or without being recognised as formal parts of the industry.

D) Government's roles and policies: As revealed in this research, ICT's roles as a sector and a facilitator need to be acknowledged within the government's policies and narratives, which are well documented in the responses of our interviewees and Bangladeshi Government 
publications. We have also found that these two roles of ICT are not independent of one another, but rather complementary, as they have mutual influence and support for each other. Tariff-free import of computer accessories, government's encouragement for promoting and developing the software industry and the commitment to integrate the digital culture in public and private business processes are some of the significant factors that have helped the development of the ICT sector and contributed to the proliferation of ICT-led development initiatives, such as mobile healthcare, support for farmers, and education. On the contrary, due to the lack of a regulatory framework, the mobile financial services are still facing challenges, as mentioned above. We can also notice vocational training on troubleshooting would have been beneficial for the aspiring traders and engineers. Further education and higher education institutes such as colleges, polytechnics and universities could have courses and programmes that address these needs. Supportive government policies in this regard can make a significant development in this regard. Hence, we concur with the current scholarship in technology upgrading by pronouncing the importance of government regulatory frameworks in the volatile business environments that constitute the inherent characteristics of developing societies. 




Figure 2 Dynamic model of technology upgrading through co-creation of value

Figure 2 summarises the findings of this research by developing a conceptual model of technology upgrading through co-creation of value. It extends the conceptual framework presented in the figure-1 and spells out the inter-relationships between various actors contributing to the technology upgrading and how those interactions foster ICT for development by generating value. The relationships are dynamic and iterative. As the figure shows, government policies and strategies reflect ICT's role as a sector and a facilitator. 
Large commercial firms, small businesses and NGOs are also involved in the co-creation of initiatives such as bKash. While some of these links and relations are direct, others are indirect. Indirect connections are defined as platform business. As Alstyne et al. (2016) suggest in a platform business there are owners, providers, producers and consumers. In our research we have found one additional component in the form of facilitators such as NGOs. As such, this paper offers evidence of platform business that transcends consumers and profit seeking businesses. All these actors nevertheless co-create value and upgrade technology, which impacts on individual users' knowledge, expertise and lifestyle. We also suggest and demonstrate a case for a shift of emphasis from the firm to the marketplace itself. We see this shift as providing a deeper understanding of the symbiotic inter-relationships among various parties that co-create an ecosystem of business models and technological innovations for these marketplaces.

Finally from the findings we could not get any strong indication to suggest that some of the crucial factors such as banking, finance and manufacturing systems have any significant place in the entire process. Particularly for SMEs in Bangladesh institutional financing is not much abundant and some of these businesses start with very little investment. As discussed in the findings the smartphone industry in Bangladesh are mostly based on imported handsets and other accessories and is not dependent on large scale manufacturing base. Furthermore, the industry is not supported by appropriate training programmes and vocational institutes which can enhance technical and entrepreneurial skills. In comparison with the other existing models in the technology upgrading, discussed in the literature, this model thereby shows how technology upgrading is achieved despite the absence of some crucial factors.

However, value can not only be created, but also be destroyed. While the relationships shown in the model explicate the potential and/or actual influences that various parties have on their counterparts, it can also be understood that any irregularities and/or difficulties in those relationships can have impact on the outcomes. For instance, a lack of regulatory framework can reduce value. The model, nevertheless does not fully explain the speed and efficiency of the processes and relationships which can be further investigated in future research.

\section{Conclusion:}

We argue that it is important to analyse the complex dynamics and iterative interrelationships between various agents within the broader socio-economic structure that not only encourage the innovation within an organisation, but also foster the creative development of an industry. 
We argue that the diffusion of innovation and its subsequent contribution to socio-economic development also encourage new product development ideas. Innovation and creativity at the organisational level can gain huge benefits from such influence. A better understanding of the market dynamics can enable an organisation to explore opportunities through mutual exchange of ideas and support, as suggested in existing literature (Burger-Helmchen and Cohendet, 2011). Furthermore, understanding of integrated roadmap is suggested to develop a holistic understanding of the market drivers that can be crucial for future oriented organisations' innovation and product development (Vishnevskiy et al. 2015 a \& b). However, we demonstrate that the complex interactions within the business environment resulting from the diffusion of innovation can also enable organisations to obtain new product development ideas and/or alter existing marketing strategies. This effectively closes the loop and shows that the innovations on both sides of the market spectrum can help each other and lead to a more sustained growth for creative economies.

This paper makes a significant contribution to the current understanding of how mutually beneficial and symbiotic businesses in developing countries can formulate the co-creation of value and thereby contribute to technology upgrading. It presents a robust and holistic model that explicates the inter-relationships between various parties. Although some of the issues and findings presented and discussed in this paper are context-specific, there are several general issues which transcend geographic and contextual boundaries. For instance, troubleshooting and user-end innovation are common in other contexts. However, troubleshooting can be particularly important in the context of developing countries, as large smartphone manufacturers have limited reach and after-sales services in most parts of these countries.

Based on our findings, we argue that digital technologies are neither a magic solution nor malleable to individual or collective dominance. Rather, the contextual and reciprocal influence between the technology, individual users, SMEs and/or their communities shapes their use and creates value. Furthermore, regular and interactive dialogue between customers and organisations is imperative for new technological development and alteration of existing technologies. For instance, the wide use of jailbreaking in South Asian countries is an indication that customers are willing to exercise freedom, innovation and adaptation, and small businesses are quick to take that opportunity if large multinationals choose to ignore or inhibit them. 
The current paper provides exploratory and indicative findings that could be further investigated in country-specific contexts in other parts of South Asia and beyond. Projects, policies and initiatives were assessed on the basis of secondary research and interview responses. Although cross-checking and triangulation were conducted to check and verify the claims, there might still be biased and short-sighted opinions. A longitudinal study with researcher observation could potentially overcome this limitation.

\section{References:}

Abraham, R. (2007), "Mobile phones and economic development: evidence from the fishing industry in India”, Information Technologies and International Development, Vol. 4, No.1, pp.5-17.

Aker, J.C. and Mbiti, I.M., (2010), "Mobile phones and economic development in Africa", Economic Perspectives, Vol. 24, No. 3, pp. 207-232.

Alalwan, A. A., Dwivedi, Y. K., Rana, N. P., Lal, B., and Williams, M. D. (2015), "Consumer adoption of Internet banking in Jordan: Examining the role of hedonic motivation, habit, self-efficacy and trust", Journal of Financial Services Marketing, Vol. 20, No.2, pp.145-157.

Alstyne, M.W.V., Parker, G.G. and Choudary, S.P. (2016), "Pipelines, platforms and the new rules of strategy", Harvard Business Review, April, pp 1-9.

Aminuzzaman, S., Baldersheim, H. \& Jamil, I. (2003), “Talking back! Empowerment and mobile phones in rural Bangladesh: a study of the village phone scheme of Grameen Bank", Contemporary South Asia, Vol. 12, No.3, pp. 327 - 348.

Anderson, P. and Rosengvist, C. (2007), "Mobile innovations in healthcare: customer involvement and co-creation of value", International J. Mobile Communication, Vol. 5, No.4, pp.371-388.

Barringer, B.R. and Harrison, J.S. (2000), "Walking a tightrope: creating value through interorganizational relationships", Journal of Management, Vol. 26, No.3, pp.367403.

Bayes, A. (2001), "Infrastructure and rural development: insights from a Grameen Bank village phone initiative in Bangladesh”, Agric. Econ Vol. 25, pp.261-272.

Burger-Helmchen, T. and Cohendet, P. (2011), "User communities and social software in the video grame industry”, Long Range Planning, Vol.44, No. 5-6, pp. 317-343. 
Bruno, R.L., and Campos, N.F. (2013), "Reexamining the Conditional Effect of Foreign Direct Investment”, IZA Discussion Paper No. 7458, June 2013.

Cattaneo, O., Gereffi, G., and Staritz, C. (2010), Global value chains in a postcrisis world: a development perspective, World Bank Publications.

Chen, L. and Nath, R. (2004), "A framework for mobile business applications", International Journal of Mobile Communications, Vol. 2, pp.368-381.

Chen, H., Nunes, M.B., Zhou, L. and Peng, G.C. (2011), "Expanding the concept of requirements traceability: the role electronic records management in gathering evidence of crucial communications and negotiations", Aslib Proceedings: New Information Perspectives, Vol. 63, No. 2/3, pp. 168-187.

Chenery, H. and Syrquin, M. (1975), "Patterns of Development, 1950-1970”, (World Bank), Oxford: Oxford University Press.

Del Prete, D., Rungi, A. (2015), “Organizing the Global Value Chain: a firm-level test”, EIC working paper series \#4/2015 IMT Institute for Advanced Studies Lucca.

Dey, B. L., Binsardi, B., Prendergast, R. \& Saren, M. 2013. A qualitative enquiry into the appropriation of mobile telephony at the bottom of the pyramid. International Marketing Review, 30, 297-322.

Dey, B.L., Pandit A., Saren, M., Bhowmick, S. and Woodruff-Burton, H. (2016). Co-creation of Value at the Bottom of the Pyramid: Analysing Bangladeshi Farmers' Use of Mobile Telephony, Journal of Retailing and Customer Services, 29, 40-48.

Donner, J. (2006), "Research approaches to mobile use in the developing world: a review of the literature", Conference paper presented at the International Conference on Mobile Communication and Asian Modernities, City University of Hong Kong, available at: (http://research.microsoft.com/ jdonner).

Donner, J. (2008), “The rules of beeping: exchanging messages via intentional missed calls on mobile phones", Journal of Computer Mediated Communication, Vol. 13, pp 1-22.

Donner, J. and Escobari, M. X. (2010), “A review of evidence on mobile use by micro and small enterprises in developing countries",Journal of International Development, Vol 22, pp 641-658.

Dwivedi, Y. K., Khan, N., and Papazafeiropoulou, A. (2007), “Consumer adoption and usage of broadband in Bangladesh", Electronic Government, an International Journal, 4(3), 299-313. 
Ernst, D. (2008), “Asia's "upgrading through innovation" strategies and global innovation networks: an extension of Sanjaya Lall's research agenda", Transnational Corporations, Vol.17, No.3, pp. 22-44. December.

Ernst, D. (2014), Upgrading India's Electronics Manufacturing Industry: Regulatory Reform and Industrial Policy, Honolulu: East West Centre.

Fereday, J. and Muir-Cochrane, E. (2006), "Demonstrating rigour using thematic analysis: a hybrid approach of inductive and deductive coding and thematic development", International Journal of Qualitative Methods, Vol. 5, No. 1, pp. 1-11.

Fors, M. and Moreno, A. (2002), "The benefits and obstacles of implementing ICT strategies for development from a bottom-up approach”, Aslib Proceedings, Vol. 54, No. 3, pp 198-206.

Fu, X., Pietrobelli, C., Soete, L. (2011) 'The role of foreign technology and indigenous innovation in the emerging economies: technological change and catching-up', World Development, Vol. 39 No. 7, pp. 1204-1212.

Foster, C., and Heeks, R. (2013), "Innovation and scaling of ICT for the bottom-of-thepyramid”, Journal of Information Technology, Vol. 28, No. 4, pp.296-315.

Gereffi, G. (2005), "The Global Economy: organization, governance and development" in N.J Smelser and R. Wedberg (editors), The Handbook of Economic, Sociology, 2nd ed. Princeton University Press: Sage Foundation.

Gereffi G \& Memedovic, O, 2004. Inserting Local Industries into Global Value Chains and Global Production Networks: Opportunities and Challenges for Upgrading. Vienna: UNIDO.

Gibson, C. \& Kong, L. 2005. Cultural economy: a critical review. Progress in human geography, 29, 541-561.

Greenshaw, E.M. and Robinson, K. (2006), "Globalisation and the digital divide: the role of structural conduciveness and global connection in internet diffusion", Social Science Quarterly, Vol.87, No.1, 90-207.

Grönroos, C. \& Voima, P. 2013. Critical service logic: making sense of value creation and co-creation. Journal of the Academy of Marketing Science, 41, 133-150.

Heeks, R. and Jagun A. (2007), “m-Development: Current issues and Research Priorities”, Short paper by Development Informatics", IPDM, University of Manchester, available at: http://www.sed.manchester.ac.uk/idpm/research/publications/wp/di/index.htm\#sp accessed on 21/06/ 2017. 
Heinoen, K., Strandvik, T. and Voima, P. (2013), "Customer dominant value formation in service”, European Business Review, Vol. 25, No.2, pp.104-123.

Hermerking, M. (2005), "Culture and Internet consumption: contribution from cross cultural marketing and advertising research", Journal of computer-mediated communication, Vol. 11, pp 192-216.

Hobday, M. (1995) 'East Asian latecomer firms' learning the technology of electronics', World Development, Vol 23 No. 7, pp. 1171-1193.

Hollebeek, L. D. \& Brodie, R. J. (2009), "Wine service marketing, value co-creation and involvement: research issues", International Journal of Wine Business Research, Vol.21, pp.339-353.

Jackson L.A., Eye, A.V., Barbatasis, G., Biocca, F., Fitzgerald, H.E. and Zhao, W. (2005), "Instructional set and Internet use by low-income adults", Cyber Psychology and Behaviour, Vol. 8, No.5, pp 465-472.

Jindra, B., Dominguez Lacasa, I., Radosevic, S. (2015) 'Dynamics of Technology Upgrading of the Central and East European Countries in a Comparative Perspective: Analysis Based on Patent Data', Economics and Business Working Paper No.135, UCL SSEES Centre for Comparative Economics, February 2015.

Kaplinksy, R. (2004), "Spreading the gains from globalization: what can be learned from value chain analysis?", Problems of Economic Transition, Vol. 47, pp.74-115.

Kapoor, K. K., Dwivedi, Y. K., and Williams, M. D. (2015), "Empirical Examination of the Role of Three Sets of Innovation Attributes for Determining Adoption of IRCTC Mobile Ticketing Service", Information Systems Management, Vol. 32, No.2, pp153173.

Karnani, A. (2012), "Markets of the poor: Opportunities and limits", International Journal of Rural Management, Vol. 8, No. 1\&2, pp.7-17.

Kim, L. (1997) Imitation to Innovation: The Dynamics of Korea's Technological Learning. Harvard Business School Press, Boston.

Lall, S. (1992) 'Technological capabilities and industrialization', Research Policy, Vol. 20 No. 2, pp. 165-186.

Lee, K. (2013), Schumpeterian Analysis of Economic Catch-up, Knowledge, Path-creation and the Middle-Income Trap, Cambridge: Cambridge University Press.

Lee, K. and Lim, C. (2001) 'Technological regimes, catching-up and leapfrogging: Findings from Korean industries', Research Policy, Vol. 30 No. 3, pp. 459-483. 
Lee, S. M., Olson, D. L., and Trimi, S. (2012), "Co-innovation: convergenomics, collaboration, and co-creation for organizational values", Management Decision, Vol.50, No. 5, pp. 817-831.

Lin, J.Y. (2012) 'From flying geese to leading dragons: new opportunities and strategies for structural transformation in developing countries', Global Policy, Vol. 3 No. 4, pp. $397-409$.

London, T. (2016). The Base of the Pyramid Promise: Building Businesses with Impact and Scale. Stanford, CA: Stanford Business Books.

Lundvall, B.A., 2010. National Systems of Innovation: Towards a Theory of Innovation and Interactive Learning: Anthem Press.

Mostafa, R. and Klepper, S. (2017), "Industrial development through tacit knowledge seeding: evidence from Bangladesh garments industry", Management Science, available

at: https://pdfs.semanticscholar.org/41f9/803132d7945df65d032fbe417727e3c4f25b.pdf, last accessed on 22/09/2017.

Mariscal, J. (2005), "Digital divide in a developing country", Telecommunication Policy, Vol. 29, pp 409-428.

Mutula, S.M. and Mostert, M.J. (2010), "Challenges and opportunities of e-government in South Africa", The Electronic Library, Vol. 28 Iss 1 pp. 38 - 53

Orlikowski, W. J. (1992), "The duality of technology: rethinking the concept of technology in organisations", Organisation Science, Vol. 3, No.3, pp 398-427.

Pavlinek, P and Zenka, J. (2010), “The 2008-2009 automotive industry crisis and regional unemployment in Central Europe", Cambridge Journal of Regions, Economy and Society, Vol. 3, pp. 349-365.

Perez-Almen, P. (2011), “Agriculture Development and Nutrition Society Special Feature: Global Standards and Local Knowledge Building: Upgrading Small Producers in Developing Countries" accessed from: http:/www.pnas.org, accessed on 27/09/2017.

Perez, C. and Soete, L. (1988) 'Catching up in technology: Entry barriers and windows of opportunity', in Dosi, G., Freeman, C., Nelson, R. et al. (eds.) Technical Change and Economic Theory, Printer Publishers, London, pp. 458-479.

Pick, J. B., Gollakota, K., and Singh, M. (2014), "Technology for development: Understanding influences on use of rural telecenters in India”, Information Technology for Development, Vol.20, No.4, pp. 296-323. 
Payne, A.F., Storbacka, K. and Frow, P. (2008), "Managing the co-creation of value", Journal of the Academy of Marketing Science, Vol.36, pp.83-96.

Prahalad, C. K. (2012), "Bottom of the Pyramid as a Source of Breakthrough Innovations", Journal of Product Innovation Management, Vol. 29, No.1, pp.6-12.

Prahalad, C.K., Hart. S.L. (2002) The Fortune at the Bottom of the Pyramid, Strategy + Business, vol. 26, pp. 1-16

Prahalad, C.K. and Ramaswamy, V. (2004), "Co-creation experiences: The next practice in value creation", Journal of Interactive Marketing, Vol. 18, No. 3, pp.5-14.

Pongsakornrungsilp, S. \& Schroeder, J. E. (2011), "Understanding value co-creation in a coconsuming brand community", Marketing Theory, Vol.11, 303-324.

Rahman, S.A., Taghizadeh, S.K. Ramayah, T. and Alam, M.M.D. (2017), “Technology acceptance among micro-entrepreneurs in a marginalized social strata: The case of social innovation in Bangladesh", Technological Forecasting and Social Change, (Article in press: http://dx.doi.org/10.1016/j.techfore.2017.01.027).

Radosevic, S. and Yoruk, E. (2014), “Are there global shifts in world science base? Analysis of catching up and falling behind of world regions", Scientometrics, Vol. 101, pp. 1897-1924.

Radosevic, S. and Yoruk, E. (2016), "Why do we need theory and metrics for technology upgrading?" Asian Journal of Technology Innovation, Vol. 24, No. SI, pp. 8-32.

Rashid, A.T. and Elder, L. (2009), "Mobile phones and development: an analysis of IDRCsupported projects", Electronic Journal of Information Systems in Developing Countries, Vol. 36, No. 2, pp 1-16.

Rashid, T. A., and Rahman, M. (2009), "Making profit to solve development problems: the case of Telenor AS and the Village Phone Programme in Bangladesh", Journal of Marketing Management, Vol. 25, No.9-10, pp.1049-1060.

Ravald, A. and GRONROOS, C. (1996), "The value concept and relationship marketing”, European Journal of Marketing, Vol. 30, No.2, pp.19-30.

Razzaque, M.A. (1997), "Challenges to logistics development: the case of a Third World country Bangladesh", International Journal of Physical Distribution and Logistics Management, Vol. 27, No.1, pp. 18-38.

Reck, J. and Wood, B. (2003), "What works for Vodacom community service phones: providing telecommunication to poor communities in South Africa", Case study by Infordev and USAID, available 
http://lyceum.algonquincollege.com/swbp/africa/lessonPlans/lesson41/documents/Voda com.pdf, last accessed on 22/09/2017.

Ritchie, B. (2010), Systemic Vulnerability and Sustainable Economic Growth: Skills and Upgrading in Southeast Asia. Cheltenham: Edward Edgar Publishing.

Rostow, W.W. (1960), The Stages of Economic Growth: A Non-Communist Manifest (2nd enlarged edn., 1971), Cambridge: Cambridge University Press.

Saarijarvi, H., Kannan, P.K., and Kuusela, H. (2013), "Value co-creation: theoretical approaches and practical implications", European Business Review, Vol. 25, No.1, pp.6-19

Sandström, S., Edvardsson, B., Kristensson, P. \& Magnusson, P. (2008), "Value in use through service experience", Managing Service Quality: An International Journal, Vol.18, pp.112-126.

Spohrer, J. and Maglio, P. P. (2008), "The emergence of service science: Toward systematic service innovations to accelerate co-creation of value", Production and operations management, Vol. 17, No.3, pp.238-246.

Stevens, C.H. (1990), "Cotechnology in the global 90s", Journal Social and Biological Structure, Vol.13, No. 2, pp. 119-140.

$\mathrm{Su}, \mathrm{H}$. and Moaniba, I.M. (2017), "Investigating the dynamics of interdisciplinary evolution in technology developments", Technological Forecasting and Social Change, Vol. 122, ppp. 12-23.

Takenaka, T. and Ueda, K. (2008), "An analysis of service studies toward sustainable value creation", International Journal of Sustainable Manufacturing, Vol. 1, No.2, 167-179

Thapa, D. and Sæbø, Ø. (2014), "Exploring the link between ICT and development in the context of developing countries: a literature review", Electronic Journal of Information Systems in Developing Countries, Vol. 64, No. 1, pp. 1-15.

Vargo, S.L., and Lusch, R.F. (2008), "Service dominant logic: continuing the evolution", Journal of the Academy of Marketing Science, Vol. 36, No.1, pp1-10.

Vargo, S. L., Maglio, P. P., and Akaka, M. A. (2008), "On value and value co-creation: A service systems and service logic perspective". European management journal, Vol. 26, No. 3, pp.145-152.

Viswanathan, M., and Sridharan, S. (2012), "Product development for the BoP: insights on concept and prototype development from university-based student projects in India, Journal of Product Innovation Management, Vol. 29, No.1, pp.52-69. 
Vishnevskiy, K., Karasev, O. and Meissner, D. (2015a), "Integrated roadmaps and corporate foresight as tools of innovation management: The case of Russian companies", Technological Forecasting and Social Change, Vol. 90, pp. 433-443.

Vishnevskiy, K., Karasev, O. and Meissner, D. (2015b), "Strategic foresight: state-of-the-art and prospects for Russian corporations", Foresight, Vol. 17, No.5, pp. 460-474.

Von Tunzelmann, G.N. (1995), Technology and Industrial Progress: The Foundations of Economic Growth, Aldershot: Edward Elgar.

Walsham, G. (2010), "ICTs for broader development in India: an analysis of the literature", Electronic Journal for Information Systems in Developing Countries, Vol. 41, No.4, pp 1-20.

Willis, S. and Tranter, B. (2006), "Beyond the digital divide: internet diffusion and inequality in Austrilia", Journal of Sociology, Vol. 42, No.1, pp 43-59.

Yoruk, D.E. (2013), 'Firm-level upgrading in low- and medium-technology industries in emerging markets: the role of learning networks', Ph.D. thesis, University of Sussex, December, SPRU. 